\title{
A CLINICAL CORRELATION BETWEEN ENCEPHALOPATHY AND PAPILLOEDEMA IN ADDISON'S DISEASE
}

\author{
BY \\ ANTONY JEFFERSON * \\ From the Department of Neurological Surgery, Radcliffe Infirmary, Oxford
}

The possibility that papilloedema may occur in Addison's disease other than as a chance coincidence is not widely known. It has been possible to trace two accounts, both published since 1950, where this has been noted. This article provides an account of a third, very similar, case and also reports gross cerebral oedema in two other patients with adrenal insufficiency. Of these two patients, one had early papilloedema, and the adrenal failure was secondary to a small chromophobe adenoma of the pituitary gland. For the other patient the oedema was a feature of the postmortem findings, but the death was so sudden and unexpected that the fundi had not been examined carefully. In discussing these patients a part of the relevant literature is surveyed and some facts about the occurrence of cerebral oedema in Addison's disease will be considered.

\section{Case Reports}

Case 1 (R.I. No. 164357/52).-The patient, a girl aged 17 , was unmarried. No one in the family had had any illness similar to hers. She herself had not had tuberculosis nor was she known to have been exposed to the infection. She had never had fits.

In her past history there was nothing relevant except that her periods began when she was aged 9 and they had since been regular. The last period, which occurred two weeks before admission, was rather scanty. She had recently lost half a stone in weight. Her weight was not recorded, but it was noted that she was thin and had a poor appetite.

For a few months before admission she had found that she became short of breath when walking. There had been no ankle oedema.

Three months before admission she fell off a chair and hit her head against the wall. There was no loss of consciousness, but she did get a generalized headache which made her lie on her bed and sleep for two or three hours. She then got up for a short time but returned to bed for the rest of that day, as the back of her head was aching. The next day she felt well. Nothing further was noted until one month later when bifrontal

\footnotetext{
* Nuffield Foundation Fellow.
}

headaches started. Initially these were mild, occurring at any time of day and lasting one or many hours. Bending down made the headaches worse. At first they occurred twice or three times a week, but as they became more severe they also became more frequent; on this account she was unable to continue her work in a dairy. She gave up reading during this period because her eyes ached when she did so. One month before admission she began to vomit, sometimes several times daily.

Three weeks before admission she fainted while standing in a bus and there were three similar "faints", all while she was standing. There were no convulsions, tongue biting, or incontinence to suggest that these were epileptic attacks.

These symptoms led to her admission to hospital, where bilateral papilloedema and bilateral extensor plantar responses were observed. Because of these findings an intracranial tumour was suspected and arrangements were made for her transfer to the neurosurgical department. Shortly before transfer she noticed some vertigo when she tried to get up from her bed ; she also developed fairly persistent hiccoughs.

On admission she was found to be thin and pale. The veins in the temples were abnormally prominent. Her neck was stiff. She was not completely orientated and did not cooperate fully in the examination. She would not attempt simple arithmetical tests. She was not dysphasic but there was some dysarthria.

The fundi showed bilateral papilloedema of about 3 dioptres with a little exudate in the right fundus. The fields were full to a $5 \mathrm{~mm}$. white object at 2 metres on the Bjerrum screen. Both the blind spots were enlarged. The visual acuities were normal.

She had an inconstant nystagmus on lateral gaze. There were otherwise no abnormalities in the cranial nerves. On formal bed tests the limbs showed generalized hypotonia and loss of power, together with some loss of facility in rapid coordinated movements. She objected to standing on account of the giddiness which resulted, but when persuaded to do so walked on a wide base unsteadily, deviating inconstantly to one side or the other. None of the deep tendon reflexes could be elicited. The superficial abdominal reflexes were all equally brisk. Both plantar responses were extensor. There was no disturbance of sensation. 
There was no abnormal pigmentation of the skin or of the mucosae. The body hair was normal in distribution. The pulse rate was 110 per min., regular but rather feeble. The blood pressure was $95 / 50 \mathrm{~mm}$. Hg. Examination of the chest revealed no abnormality. She would not relax the muscles sufficiently to allow satisfactory palpation of the abdomen.

Electroencephalography showed "sleep spindles" at 12 to 13 per sec. in the parasagittal leads. They were best seen in the frontal and fronto-parietal regions and occurred on a background of $5 / \mathrm{sec}$. waves. A curious feature was that the E.E.G. pattern (Fig. 1), which was one consistent with light sleep, remained unchanged whether the patient's eyes were open or shut and, throughout the recording, she was able to obey simple commands.

The main clinical features of the case made it reasonable to suspect an intracranial tumour, and in order to gain more information biparietal burr-holes were made under local anaesthesia and a ventriculogram was done. The ventricles, which were small, were found in the normal position. Air was injected and the radiographs taken subsequently excluded any kind of intracranial tumour, but suggested the presence of cerebral oedema because of the sharpness of the angles of the lateral ventricles. The cause of this oedema was not identified.
While the radiographs were being taken it was dis- $Z$ covered that the pulse could scarcely be felt and the systolic blood pressure was estimated to be $\mathbf{4 0} \mathrm{mm}$. Hg. The possibility of acute suprarenal insufficiency was considered and arrangements were made to give " eucortone" and intravenous fluids. However, beforew these were actually begun the blood pressure rose to $100 / 70 \mathrm{~mm}$. Hg. (Chloride, sodium, and potassium studies were done immediately after the collapse ; in $\vec{z}$ retrospect these suggested an impending Addisonian: crisis but their significance was not grasped at the time, the picture having been confused by the clinicato features of the case.) Eucortone, $40 \mathrm{ml}$., and 1,800 ml. $\frac{\bar{\sigma}}{\mathrm{C}}$ of fluid were given intravenously. Her blood pressure did $\overline{\bar{p}}$. not rise any further, and because her improvement ante- $\bar{\nabla}$ dated the intravenous therapy it was difficult to assess $\varrho$ how much further livening in her state could be attribu-» ted to the "eucortone" and the fluid intake. The $\rightarrow$ intravenous medication was stopped both for lack of definite evidence that it was beneficial and out of fear $\vec{\omega}$ of making the cerebral oedema worse. The patient ${ }^{\omega}$ continued restless and disorientated, her blood pressure remaining in the region of $90 / 50$ until she quietly and suddenly died some 36 hours after the ventriculogram.-

At necropsy the lungs were normal. The heart was. small, weighing $170 \mathrm{~g}$. All the abdominal organs werer normal with the exception of the suprarenal glands whieh -
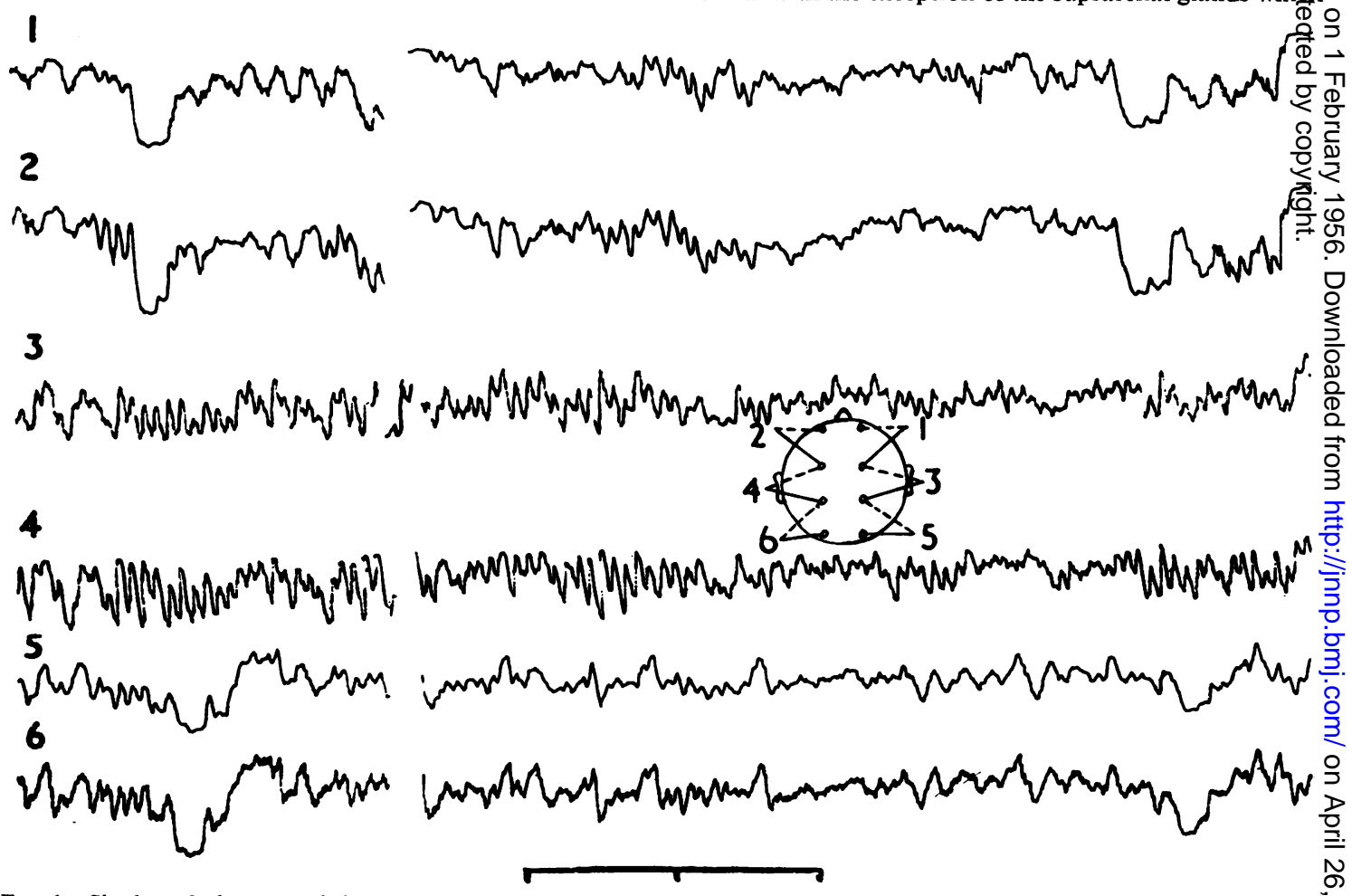

FIG. 1.-Six-channel electroencephalogram recorded from Case 1. Diagram indicates position of electrodes. Big slow waves at the $\mathrm{N}$ left- and right-hand ends of this record are caused by eyeblinks confirming that the patient was " awake" during the recording. Record, however, shows fast beta activity closely resembling sleep spindles. (Time marker $=1$ sec. intervals.) 


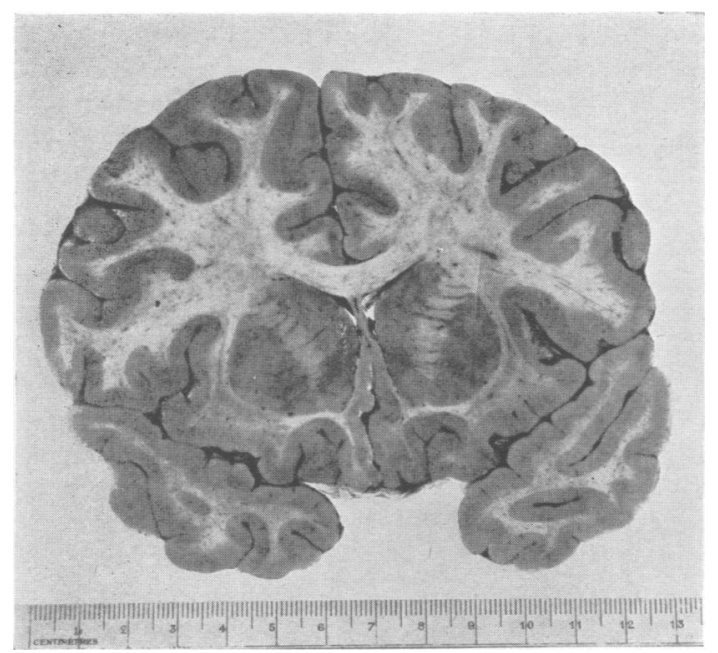

FIG. 2.-Coronal section through the frontal region to show the pathologically small lateral ventricles in Case 1.

weighed $3 \mathrm{~g}$. each (normal 3.5 to $6.0 \mathrm{~g}$.). On section they appeared thin and grey and there was no macroscopical evidence of yellow cortical tissue. Although a search was made for aberrant cortical tissue, none was found. Microscopical sections showed that though the adrenal medulla was intact, the cortex was entirely absent in many places and only a few islands of cortical cells were left. The blood vessels in what remained of the adrenal cortex were unduly prominent and there was some lymphocytic infiltration in the gland.

The thymus was larger than is usual at this age : it weighed $22 \mathrm{~g}$. and had two main lobes and a smaller central lobe. Among the lymph glands the cervical glands alone were enlarged, a possible result of the fact that the tonsils were enlarged and infected. The thyroid weighed $12 \mathrm{~g}$. (normal 30 to $40 \mathrm{~g}$.) and lymphoid follicles were scattered among the colloid vesicles. The parathyroids were not found. The pituitary appeared normal but no detailed cell counts were done.

The brain weighed 1,430 g. (normal 1,230 g.). The meninges were normal with no suspicion of exudate. Examination of the base of the brain showed slight grooving of the right uncus and slight herniation of the right tonsil. These changes were not definite enough to indicate that herniation of an oedematous brain either at the tentorial hiatus or at the foramen magnum had contributed to her death. When the brain was sectioned it was found to be very full and the ventricles were small (Fig. 2). It was somewhat congested. Microscopical examination confirmed the presence of oedema and, disposed around occasional vessels, there were collections of " round cells".

Case 2 (R.I. No. 9798/43). - This 23-year-old single man had, from the age of 10 years, been subject to episodes of loss of appetite, refusal to drink, and mild headache, each lasting two to three days at a time. As he grew older he was observed to be unusual in that he never needed to shave, the body remained almost hairless, and the genitalia were underdeveloped.

Eighteen months before admission he was first aware of visual failure. In view of the features of suprarenal and other endocrine deficiencies, operation was deferred for some four months after the diagnosis of chromophobe pituitary adenoma had been made.

He was rather obese, and had a blood pressure of $90 / 60 \mathrm{~mm}$. $\mathrm{Hg}$, falling to $50 \mathrm{~mm}$. $\mathrm{Hg}$ (systolic) on standing. As mentioned above, the secondary sex characteristics were not normally developed. Both optic discs were pale, and in addition showed early papilloedema. Vision in the left eye was reduced to hand movements, and in the right eye, although normal acuities were preserved, there was a dense temporal field defect. There were no other significant neurological abnormalities. The skull showed increased " digital impressions" suggesting raised intracranial pressure.

At operation (June 23, 1943, Mr. J. B. Pennybacker) the brain was so tight as to make considerable technical difficulties. During the course of the operation it was demonstrated that the "tightness" was not due to a big tumour nor to obstructed lateral ventricles; in fact, the lateral ventricles were unusually small and undisplaced. At the time, the significance of this observation was not known, but in the light of the cases recorded here it may be surmised that this patient also had cerebral oedema associated with the clinical evidence of suprarenal insufficiency. However, since the patient survived the operation, proof of this contention is not possible.

The finding of papilloedema in association with Addison's disease as occurred in Case 1 might be regarded as a mere coincidence were it not that two further very similar cases have been reported in the literature since 1950.

Case of Boudin, Funck-Brentano, and Gayno (1950). This concerned a girl of 23 whose periods had begun at the age of 10. She had her first pregnancy aged 14 and her second aged 21 , after which she developed persistent fatigue. Three months before admission she developed a severe and continuous occipital headache. Her gait was unsteady. She was referred to hospital because these symptoms had led to the discovery that she had considerable bilateral papilloedema.

In view of the story of headache, vomiting, and ataxia associated with papilloedema, she was admitted with a provisional diagnosis of cerebellar tumour. The general examination disclosed a slight generalized pigmentation of the skin.

A ventriculogram was proposed but the patient became acutely ill during the procedure. Her blood pressure fell to a very low level. Tapping the ventricles had provided information which made a cerebellar tumour unlikely, and the examination was discontinued without outlining the ventricular system by the injection of air.

Because the patient was considerably anaemic (R.B.C. 2,500,000) she was treated with vitamin $B_{12}$ in the first instance and her general condition improved ; the papilloedema also regressed. However, in spite of the 
continued administration of vitamin $\mathbf{B}_{12}$ the patient relapsed and was started on a régime of $10 \mathrm{mg}$. D.O.C.A. and $6 \mathrm{~g}$. salt daily. About five or six weeks after the beginning of all treatment the fundi were slightly blurred and the veins dilated.

This patient unfortunately died some two to three weeks later in an acute allergic reaction whose precipitating cause was not identified.

At necropsy it was impossible to find the suprarenal glands and presumably they were either aplastic or atrophied. The pituitary gland appeared normal. Necropsy confirmed that there was no intracranial tumour and showed diffuse and considerable cerebral oedema. The significance of the latter finding is difficult to gauge in the presence of bilateral acute pulmonary oedema secondary to the anaphylactic reaction.

Case of Walsh (1952). - This concerned a girl of 20 who had been anaemic for five years following severe pyelonephritis. Five months before admission to hospital she began to complain of excessive fatigue and of headache associated with vomiting. The diagnosis of Addison's disease had been made three months before admission.

At the time of her admission to hospital she was extremely feeble and had a severe headache and was vomiting. She had no complaints referable to the eyes. On the right side there were 3 dioptres of papilloedema and on the left side 4 dioptres. The blind spots were correspondingly enlarged. There were superficial freshlooking exudates associated with the papilloedema but no haemorrhages. The retinal veins were full. Her blood pressure was $90 / 60 \mathrm{~mm}$. $\mathrm{Hg}$.

In view of the headache, vomiting, and papilloedema it was initially intended to investigate the nervous system. However, a lumbar puncture was not thought advisable in the presence of such a degree of papilloedema, and the dangers of ventriculography in the presence of suprarenal insufficiency were recognized. It was suggested that the papilloedema might have resulted from thrombosis of the intracranial dural sinuses and the decision was taken to treat the patient with D.O.C.A. and with cortisone and to await results.

The results were impressive. After four weeks of treatment the headache had disappeared and the blood pressure was near normal. The papilloedema had subsided to 2 dioptres. Three months later there was only slight blurring of the discs and the exudate had gone. At the time of publication the patient was still alive and well.

\section{" Encéphalopathie Addisonienne"}

Thomas Addison's paper " On the Constitutional and Local Effects of Disease of the Supra-renal Capsules" (1855) described 11 patients who came to necropsy. In seven of these the brain was not examined ; in one the brain was normal, two showed atrophy, and in one (Case 4) the grey matter of the cerebrum was of a rather deep colour. The brain was in other respects normal. Presumably there was no oedema noted. Ettlinger and Nageotte $\overline{\mathcal{Z}}$ (1896) reported that in animals cerebral oedema $\frac{\bar{c}}{0}$ was a frequent finding after ablation of the suprarenals. They considered the possibility that thisc might not be specific, but might be "agonal " in origin.

Klippel (1899) coined the term " encéphalopathie $\frac{\rho}{\overline{2}}$ addisonienne" in relation to a 57-year-old man with typical clinical features of Addison's disease who had two fits, the first 10 days before his admission and the second immediately before admission. $\bar{C}$ He was under observation for some time and was observed to have episodes of abnormal behaviour, $\overline{\bar{S}}$ some of which apparently culminated in convulsions. Eventually the patient died in coma. Necropsy revealed both fibrous tuberculosis of the lungs and ${ }^{\infty}$ caseating tuberculous lesions which had destroyed $\vec{\circ}$ the suprarenal glands. The meninges were normal. $\overrightarrow{\vec{\omega}}$ The brain was oedematous. Microscopic study ${ }_{\sigma}^{\omega}$ showed the arterioles in the grey matter to be hyperaemic, and from these vessels there had been diapedesis of numerous round cells.

The cerebral oedema observed in this case may well have been similar to that recorded in Case 1.

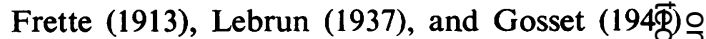
all published theses which concerned themselveswith the encephalopathy of Addison's disease? Frette recounts eight case histories where adrenalo insufficiency and changes referable to the nervogs system coexisted. Some of the cases were collected from the literature and in none of them is there a reference to the appearance of the fundi. In none of the cases, save Klippel's (mentioned above), was there any cerebral oedema, though cerebralo congestion was sometimes reported. Lebrun's (1937) patient was a woman, aged 28 , admitted in semi-coma with meningism. She died the same $\frac{0}{\mathbb{D}}$ evening. At necropsy tuberculous destruction of the adrenals was revealed. The brain showed diffuse $\overrightarrow{\overline{0}}$ oedema with slight opacity of the meninges. The 3 arterioles in the grey matter were hyperaemic and diapedesis of cells had occurred into the surrounding tissues. There was some oedema of the cortical cells. Gosset's (1941) two originalo cases of Addison's disease with cerebral symptoms are of some interest but the findings are not clear cut. In the case of a man aged 25 there was 0 meningism and confusion, but the brain though congested showed only " slight oedema". The other음 patient (a woman aged 27) was admitted after $D$ stupor had lasted eight hours and died 12 hours? later. This patient had a series of opisthotonic attacks accompanied by extensor spasm. It mays be supposed that cerebral oedema had led to 0 herniation of the brain, which in turn was responsible 
for these symptoms, but this is only supposition since permission for a necropsy was not obtained.

Paulian, Bistriceanu, and Cardas (1941) report a further instance of a man with Addison's disease who presented terminally with neurological disturbances and was found at necropsy to have cerebral oedema, but the picture was complicated by the presence of a diffuse sclerosis of the brain. Wells (1930) described a series of cases of Addison's disease. His Case 4 concerned a woman (aged 51) who died after three weeks of a subacute illness which was marked by neurological symptoms and signs. At necropsy, apart from atrophy of the suprarenal glands and lymphoid infiltration of the thyroid, the brain tissue was oedematous; no other significant cerebral changes were found. Duffin (1943) reported another example of suprarenal atrophy accompanied by cerebral oedema. This patient (Duffin's Case 8) was a boy (16 years old) who had had several attacks of coma or semicoma which had brought him to hospital. He was finally admitted moribund after a short period of unconsciousness. At necropsy there was loss of suprarenal cortex, and the pituitary showed a diffuse fibrosis of the anterior lobe and a reduced volume of secretory cells. There was a normal ratio between the chromophobe cells and the acidophils but the basophils were abnormally scarce. The brain was described as oedematous and increased in weight.

Guttman's review (1930) of the pathological features of Addison's disease made no comment on changes in the fundi or in the central nervous system.

In the records of the Radcliffe Infirmary, Oxford, it has been possible to trace 19 patients in the past 10 years in whom a clinical or a post-mortem diagnosis of Addison's disease has been made. In Case 1 alone was clinical evidence of raised intracranial pressure recorded. Among the cases that came to necropsy cerebral oedema was noted on four further occasions. One patient (a woman, aged 44 , R.I. No. $116468 / 51$ ) had suffered from lassitude and headaches and after a sudden and unexpected death the brain was found to be soft and oedematous. In another patient (a woman aged 38, R.I. No. 201987/54) considerable cerebral oedema with tentorial herniation was found (brain weighed 1,258 g.) after death, but she had been artificially respired for nearly 24 hours after spontaneous respiration ceased and it is possible that the oedema developed during this phase. In the third patient (a boy aged 10, R.I. No. 200315) Addison's disease and a mild degree of diabetes mellitus were associated. Shortly before death the diabetes became less severe. Death occurred within an hour after a sudden and unexpected collapse. On the day of death there was biochemical evidence of suprarenal failure, and necropsy confirmed considerable destruction of the suprarenal cortices. The pituitary gland appeared normal. The brain weighed $1,480 \mathrm{~g}$. (normal, 1,300 g.), but it is possible that some or all of this oedema developed terminally because, following the collapse, the patient received $1,000 \mathrm{ml}$. of plasma intravenously in an effort to restore the failing circulation. The fourth patient is described below.

Case 3 (R.I. No. 147736/54). -This patient, a boy aged 3, had been in hospital seven months earlier because of convulsions. He was admitted in extremis and died within three hours. Addison's disease was suspected terminally but there was no time to begin effective treatment. He had been vomiting and had had episodes when, without losing consciousness, he " seemed in a trance". The day before death he became drowsy, listless, pale, and cyanosed. It is not known whether he complained of headaches nor is there a record of the appearance of the fundi. The post-mortem findings confirmed the diagnosis of suprarenal failure. The pituitary gland appeared normal. The brain was full and oedematous and weighed 1,319 g. (normal about 1,100 g.). On coronal section the ventricles were seen to be very small. Microscopical sections of the brain showed that, as in Case 1, a few blood vessels showed round cell " cuffing".

\section{Discussion}

In Case 1, and in the cases reported by Boudin, Funck-Brentano, and Gayno, and by Walsh, there can be no doubt that papilloedema and Addison's disease coexisted, and all of them had similar cerebral symptoms. In Cases 1 and 3 , which came to necropsy in this hospital, and in Case 2, which was observed at operation, there were no complicating factors which might have contributed to the cerebral oedema. Thus, it seems reasonable to regard the suprarenal insufficiency as responsible for the cerebral oedema. How frequently this may happen is unknown.

Cases 1 and 3 occurred in the same hospital within the space of exactly two years and, with the exception of Case 2, all four cases mentioned in the preceding paragraph were observed within a period of less than five years. These facts, taken together with the suggestive but less clear-cut evidence of the other cases mentioned, provide a firm basis for the belief that suprarenal insufficiency is responsible for the observed oedema.

If it be conceded that suprarenal insufficiency may lead to oedema of the brain or optic nerve head, it becomes of interest to know how this is 
brought about. There is as yet no definite information upon this point. There are only speculations.

Boudin and others (1950) were of the opinion that the observed oedema might result from the disturbed water metabolism known to occur in Addison's disease (e.g., Levy, Power, and Kepler, 1946). Walsh (1952), on the other hand, considered thrombosis of the intracranial dural sinuses the most likely relevant factor. In Case 1 reported here the latter possibility was considered, and a very careful examination of the dural sinuses was made at the necropsy without revealing any pathological changes in them. Moreover, sections of the brain revealed no microscopical evidence of thromboses. In Walsh's case the fundi were undoubtedly beginning to subside after only four weeks of treatment by cortisone and D.O.C.A. Most cases of "pseudotumour", in which thromboses of the dural sinuses are with good reason suspected to have occurred, have run a more prolonged course than this. Thomas (1933) and McCullagh (1941) both quote examples of patients with oedema developing at the menstrual period, who also suffered from papilloedema. In both instances the oedema of body and of nerve head subsided coincident with hormone treatment, and metabolic abnormalities may have been responsible for the oedema. It may thus be tentatively suggested that the cerebral oedema described here results from a metabolic disorder, but the matter is most certainly nonproven as yet.

Boudin and others (1950, p. 1742), in reporting their case, make the statement that this experience entitles them to speak of a definite form of pseudotumour in Addison's disease associated with cerebral oedema. The diagnosis of "pseudotumour" or "benign papilloedema" is usually attached to a patient who presents with papilloedema and indefinite neurological abnormalities which are not progressive. Moreover, general well-being of the patient is one of the features which help to make this diagnosis acceptable. However, if the papilloedema results from Addison's disease, a sense of well-being is not likely to be present.

The experience of Case 1 reported here serves as a reminder that abnormal pigmentation of the skin or mucous membrane is not a universal phenomenon in Addison's disease. The diagnosis of suprarenal failure may not be one that would readily be considered, and the present writer would suggest that Addison's disease should be included as a possible diagnosis in all cases of " benign papilloedema". This means that the serum sodium and potassium should be estimated, together with the plasma chlorides. If a suprarenal crisis is not

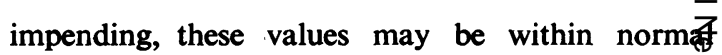
limits, and it then becomes necessary to determine the "Kepler Index" (Robinson, Power, and Kepler, 1941). Whatever the value of the index if the water metabolism is abnormal and a volume of urine smaller than normal is excreted in the fout hours after ingestion, then the test should be. repeated with $50 \mathrm{mg}$. of cortisone given by moun four hours before the loading dose of water (cf. Oleesky and Stanbury, 1951). If cortison restores to normal the amount of water excreted in the first four hours, then a trial period of regulaf cortisone therapy should be begun. Cortisong; $12.5 \mathrm{mg}$. eight-hourly, should suffice, with adde desoxycorticosterone acetate (D.O.C.A.) if the biochemistry is, or remains, abnormal. During the trial period of treatment careful neurologicat supervision and regular measurement of the visuat acuity and of the size of the blind spots is necessar s. Walsh's (1952) experience indicates that by the end of a month there will be clear indication of the effectiveness of such treatment.

If the possibility be borne in mind that supra renal insufficiency may lead to oedema of the optio nerve head or of the brain it should be possible to collect further information about the occurrêtee of this phenomenon and about its mechanism.

\section{Summary}

In a recent period of two years two cases come to necropsy in this hospital in which cerefral oedema and suprarenal insufficiency have associated.

One of the above cases presented with papilf oedema and slight neurological abnormalities. Two very similar cases are described in the liter 종 ture. All these three cases were observed with three years.

A search of the Radcliffe Infirmary records and of the literature has disclosed sonf further cases in which definite cerebral oedema was found at necropsy accompanying destructic or atrophy of the suprarenal cortex. In some of these examples the possibility of complicating factors cannot be excluded.

It is suggested that suprarenal failure is causal related to the oedema of the brain or a nerve head. The possible mechanisms are briefly discussed.

I would agree with Boudin, Funck-Brentang, and Gayno (1950) that this syndrome might found more commonly once the possibility of occurrence is suspected.

I am grateful to Mr. Joe Pennybacker for encouragement and advice during the preparation of this papef? I am also obliged to Dr. F. G. Hobson, to Dr. V. Sma悗 
peice, and to Dr. H. F. Ellis for permission to publish details of patients who were under their care.

I am grateful to Dr. S. Strich for her opinion on the microscopical appearance of the pathological specimens.

\section{REFERENCES}

Addison, T. (1855). On the Constitutional and Local Effects of Disease of the Supra-renal Capsules. Highley, London.

Boudin, G., Funck-Brentano, J.-L., and Gayno, M. (1950). Bull.

Soc. méd. Hop., Paris, 66, 1736.
Duffin, J. D. (1943). Arch. Path. (Chicago), 35, 649.

Ettlinger, C., and Nageotte, J. (1896). C.R. Soc. Biol. (Paris), 10 ser., 3, 966.

Frette, L. (1913). Contribution à l'étude de l'Insuffisance Surrénale aiguè à forme encéphalopathique. Thèse, Paris.
Gosset, A. E. M. (1941). L'Encéphalopathie addisonienne. Thèse, Bordeaux.

Guttman, P. H. (1930). Arch. Path. (Chicago), 10, 742, 895.

Klippel, M. (1899). Rev. neurol. (Paris), 7, 898.

Lebrun, R. (1937). Contribution à l'étude de l'encéphalopathie addisonienne. Thèse, Paris.

Levy, M. S., Power, M. H., and Kepler, E. J. (1946). J. clin. Endocr., 6,607 .

McCullagh, E. P. (1941). Cleveland clin. Quart., 8, 202.

Oleesky, S., and Stanbury, S. W. (1951). Lancet, 2, 664.

Paulian, D., Bistriceanu, J., and Cardas, M. (1941). Bull. Soc. méd. Hôp. Paris, 57, 34.

Robinson, F. J., Power, M. H., and Kepler, E. J. (1941). Proc. Mayo Clin., 16, 577.

Thomas, W. A. (1933). J. Amer. med. Ass., 101, 1126.

Walsh, F. B. (1952). Arch. Ophthal. (Chicago), 47, 86.

Wells, H. G. (1930). Arch. Path. (Chicago), 10, 499. 